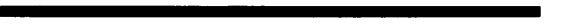 \\ LETTERS TO THE EDITOR}

\section{Palliative care for children with cancer}

SIR,-The article by Dr Goldman et al on palliative care for children with cancer described the work of the symptom care team in the department of haematology and oncology at the Hospital for Sick Children, Great Ormond Street. ${ }^{1}$ However, we feel they made light of the problem of distance between the tertiary hospital and the child's home $66 \%$ more than 20 miles). Furthermore, little more than lip service was paid in the article to the expertise of the local paediatric team.

Given the right support most children can be looked after at home in the terminal stages of cancer or leukaemia. This support is very difficult to maintain at a distance, however, even with a symptom care team at the tertiary referral centre, particularly in the last days before the child dies. We would agree that it is really not realistic to expect the primary health care team, who may have had little or no experience of looking after a dying child and may not have been involved during the child's treatment programme, to give the kind of support which is required without help.

Most children with malignant disease will be diagnosed initially in the paediatric department of the local district hospital. Here we would suggest there should be a paediatrician who has a special interest in childhood malig nant disease and this person should remain involved with the child's managemen throughout the treatment period. This can only be done with a properly organised shared care programme and this may enable some of the treatment to be given locally as well. Provided this happens the local paediatric team will be in a strong position to play a major part in the management of the terminally ill child and in supporting the family.

At the Royal Berkshire Hospital we are able to offer a domiciliary terminal care service. With help from the family's general practitioner and with our new team of paediatric community nurses we are able to give a very high measure of support in the home where it is needed. This includes a commitment to being present whenever possible when the child dies and a commitment to give ongoing support in the period after bereavement. This domiciliary service would not be possible without a shared care approach.

Shared care between the tertiary referral centre and the district paediatric department is in practice not easy to arrange. It should allow a more family orientated programme of management and better support for parents during the treatment period. We believe that more use could be made of local paediatric expertise than is suggested in the article of Goldman et al.

C L NEWMAN CAROL BARTON HILARY RYDER Royal Berkshire Hospital. London Road, Reading, Berkshire RGI 5AN

1 Goldman A, Beardsmore S, Hunt J. Palliative as hospice? Arch Dis Child 1990;65:641-3.
Pulmonary hypertension in bronchopulmonary dysplasia

SIR,-We read the paper by Dr Bush et al on changes in pulmonary circulation in severe bronchopulmonary dysplasia with great interest. ${ }^{1}$ While we agree that some patients with bronchopulmonary dysplasia might need investigation by cardiac catheterisation, we would like to stress how much useful information can be obtained non-invasively in these patients by imaging and full Doppler ultrasound studies. In this way most congenital cardiac abnormalities can be excluded. Also when the signal of tricuspid regurgitation can be detected, a non-invasive but accurate estimation of pulmonary artery pressure can be obtained..$^{2}$ It is also possible to study the reactive component of pulmonary artery pressure in bronchopulmonary dysplasia as the following case history illustrates.

\section{Case history}

A girl twin I weighing $1240 \mathrm{~g}$ was born at 28 weeks' gestation. She required ventilation for respiratory distress syndrome for the first eight days and a further two day period of ventilation at 4 weeks of age. A ductus arteriosus was closed with indomethacin, this being confirmed by colour Doppler flow mapping. She remained oxygen dependent with clinical and radiological evidence of severe bronchopulmonary dysplasia. Electrocardiography showed right ventricular hypertrophy, and cardiac ultrasound did not show any cardiac lesion. At 11 months she was allowed home on low flow oxygen treatment.

From the age of 10 to 16 months six Doppler ultrasound studies were performed to assess pulmonary artery pressure and to study the degree of reactivity in response to hypoxia. This was part of a larger study and informed parental consent was obtained. Pulmonary artery pressure was estimated when the patient was in oxygen (arterial oxygen saturation $\left.\left(\mathrm{SaO}_{2}\right) 95 \%\right)$, desaturated in air $\left(\mathrm{SaO}_{2}\right.$ $58-85 \%)$, and when replaced in oxygen $\left(\mathrm{SaO}_{2}\right.$ $95 \%)$. The resting pulmonary artery pressure in oxygen was raised and remained fairly constant throughout the study (mean $58 \mathrm{~mm} \mathrm{Hg}$ ). Except in study IV at $\mathbf{1 6}$ months there was a clear additional reactive component when desaturation occurred (figure). Pulmonary artery pressure returned to the resting level when hypoxia was abolished (mean $57.8 \mathrm{~mm}$ $\mathrm{Hg}$ ). The reactive component of pulmonary artery pressure appeared to be dependent on the degree and duration of hypoxia. At 10 months (studies I-III) reactivity was clearly visible after five minutes in air. At 16 months (study IV) no reactivity was noted after 15 minutes in air but $\mathrm{SaO}_{2}$ fell only to $85 \%$. Two

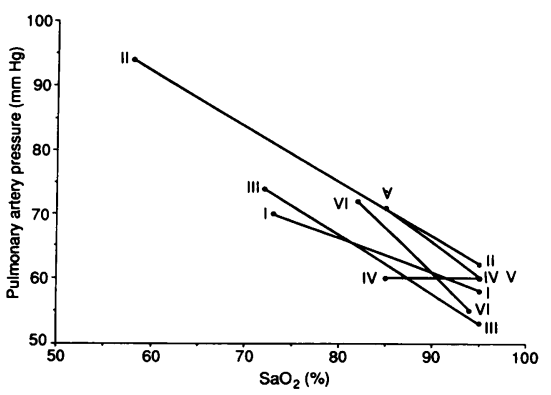

Variation in estimated pulmonary artery pressure with change in $\mathrm{SaO}_{2}$. Six studies in patient with bronchopulmonary dysplasia. weeks later (study V) reactivity was noted after 35 minutes in air $\left(\mathrm{SaO}_{2} 85 \%\right)$.

Domiciliary oxygen was continued until 23 months of age when 24 hour monitoring by pulse oximetry showed her $\mathrm{SaO}_{2}$ to remain $>95 \%$ awake, asleep, and feeding. Her pulmonary artery pressure remained raised $(58 \mathrm{~mm} \mathrm{Hg}$ ) but has subsequently fallen to 25 $\mathrm{mm} \mathrm{Hg}$ at 2.5 years of age. There is now no evidence of right ventricular hypertrophy on electrocardiography.

The signal of tricuspid regurgitation is detected by Doppler ultrasound in most normal children but its incidence in the newborn is unknown. A clear spectral envelope must be obtained for accurate estimation of pulmonary artery pressure. We have studied eight other patients with bronchopulmonary dysplasia and detected a clear tricuspid regurgitation signal in five $(62 \cdot 5 \%)$. As pulmonary artery pressure can increase with activity, sedation might be required for the older infant.

In their study on eight patients with bronchopulmonary dysplasia, Bush et al found prostacyclin to be a better vasodilator than $100 \%$ oxygen. ${ }^{1}$ In a similar cardiac catheterisation study on 15 patients with bronchopulmonary dysplasia, Goodman et al found that oxygen caused a fall in pulmonary artery pressure in all patients, the maximum fall occurring when $\mathrm{SaO}_{2}$ was $>95 \%$ but the response to a vasodilator (hydralazine) was disappointing. ${ }^{4}$ Failure of pulmonary artery pressure to normalise with oxygen was a bad prognostic sign with $50 \%$ mortality. The patients of Bush et al had a very high mortality so their poor response to oxygen might well reflect the selective nature of the group.

Cardiac catheterisation is invasive. Doppler ultrasound, where possible, allows a noninvasive estimation of pulmonary artery pressure and can be used to study whether pulmonary artery pressure normalises in oxygen thereby giving prognostic information. Perhaps cardiac catheterisation and prostacyclin treatment should be directed more to the poor prognosis group where response to oxygen is poor. For the majority of patients with bronchopulmonary dysplasia oxygen, despite its inconveniences, remains the mainstay of treatment. Indeed close attention to preventing hypoxia might even abolish a relentless rise in pulmonary artery pressure. It might also help to reduce the incidence of cot death in these patients.

M P WHITE A B HOUSTON The Royal Hospital for Sick Children, Yorkhill,

Glasgow G3 8Sf

1 Bush A, Busst CM, Knight WB, Hislop AA, Haworth SG, Shinebourne EA. Changes in pulmonary circulation in severe bronchopulmonary dysplasia. Arch Dis Child 1990;65: $739-45$.

2 Hatle L, Brubakk A, Tromsdal A, Angelsens B. Non-invasive assessment of pressure drop in mitral stenosis by Doppler ultrasound. $\mathrm{Br}$ Heart $\mathcal{f}$ 1978;40:131-40.

3 Currie PJ, Seward JB, Chan KL, et al. Continuous wave Doppler determination of right ventriuous wave Doppler determination of right ventricatheterisation study in 127 patients. $\mathcal{f ~ A m ~ C o l l ~}$ Cardiol 1985;6:750-6.

4 Goodman G, Perkin RM, Anas NG, Sperling DR, Hicks DA, Marshall R. Pulmonary hyperDR, Hicks DA, Marshall R. Pulmonary hypertension in infants with bronchopur

5 dysplasia. F Pediatr 1988;112:67-72. Keens TG 5 Garg M, Kurzner SI, Bautista DB, Keens TG. Clinically unsuspected hypoxia during sleep and feeding in infants with bronchopulm
plasia. Pediatrics 1988;81:635-42. 